\title{
Purification and biochemical properties of a cytochrome $b c$ complex from the aerobic hyperthermophilic archaeon Aeropyrum pernix
}

\author{
Yoshiki Kabashima ${ }^{1,2}$, Junshi Sakamoto ${ }^{1 *}$
}

\begin{abstract}
Background: The bioenergetics of Archaea with respect to the evolution of electron transfer systems is very interesting. In contrast to terminal oxidases, a canonical $b c_{1}$ complex has not yet been isolated from Archaea. In particular, c-type cytochromes have been reported only for a limited number of species.

Results: Here, we isolated a c-type cytochrome-containing enzyme complex from the membranes of the hyperthermophilic archaeon, Aeropyrum pernix, grown aerobically. The redox spectrum of the isolated c-type cytochrome showed a characteristic $\alpha$-band peak at $553 \mathrm{~nm}$ corresponding to heme $C$. The pyridine hemochrome spectrum also revealed the presence of heme B. In non-denaturing polyacrylamide gel electrophoresis, the cytochrome migrated as a single band with an apparent molecular mass of $80 \mathrm{kDa}$, and successive SDS-PAGE separated the 80-kDa band into 3 polypeptides with apparent molecular masses of 40, 30, and $25 \mathrm{kDa}$. The results of mass spectrometry indicated that the $25-\mathrm{kDa}$ band corresponded to the hypothetical cytochrome $c$ subunit encoded by the ORF APE_1719.1. In addition, the c-type cytochrome-containing polypeptide complex exhibited menaquinone: yeast cytochrome $c$ oxidoreductase activities.

Conclusion: In conclusion, we showed that A. pernix, a hyperthemophilic archaeon, has a "full" bc complex that includes a c-type cytochrome, and to the best of our knowledge, A. pernix is the first archaea from which such a bc complex has been identified. However, an electron donor candidates for cytochrome $c$ oxidase, such as a blue copper protein, have not yet been identified in the whole genome data of this archaeon. We are currently trying to identify an authentic substrate between a bc complex and terminal oxidase.
\end{abstract}

\section{Background}

Aeropyrum pernix is a hyperthermophilic crenarchaeon isolated from the seas of Japan, and its complete genome sequence has been reported [1,2]. Most of the hyperthermophilic archaea grow anaerobically, but this archaeon is strictly aerobic and grows optimally at 90$95^{\circ} \mathrm{C}$ at neutral $\mathrm{pH}$. Analysis of the respiratory chain of the organism is important for understanding the mechanism of aerobic growth in such environments. However, there are only a few reports about the bioenergetics of $A$. pernix.

Many bacteria and archaea have 2 to 6 terminal oxidases in the respiratory chain [3]. The heme-copper

\footnotetext{
* Correspondence: sakamoto@kyutech.ac.jp

'Department of Bioscience and Bioinformatics, Kyushu Institute of

Technology, Kawazu 680-4, lizuka, Fukuoka-ken 820-8502, Japan

Full list of author information is available at the end of the article
}

oxidase superfamily can be classified into 3 subfamilies (A-, B-, and C-type) on the basis of the amino acid sequence of subunit I $[4,5]$. The group of A-type oxidases includes mitochondrial cytochrome $a a_{3}$-type cytochrome $c$ oxidase (complex IV) and many other bacterial oxidases. In contrast, B-type oxidases have been identified mainly from extremophiles, including thermophilic bacteria, such as Geobacillus thermodenitrificans (formerly called Bacillus thermodenitrificans) [6,7] and Thermus thermophilus [8], and archaea, such as Sulfolobus acidocaldarius [9]. Analysis of the complete genome sequence of $A$. pernix has shown that it contains A- and B-type heme-copper terminal oxidases (Figure 1). Ishikawa et al. isolated 2 terminal oxidases from $A$. pernix and designated them as cytochrome $b a_{3}$ type (B-type) and $a a_{3}$-type (A-type) cytochrome $c$ oxidases, respectively [10]. Both oxidases have a $\mathrm{Cu}_{A}$

\section{() Biomed Central}




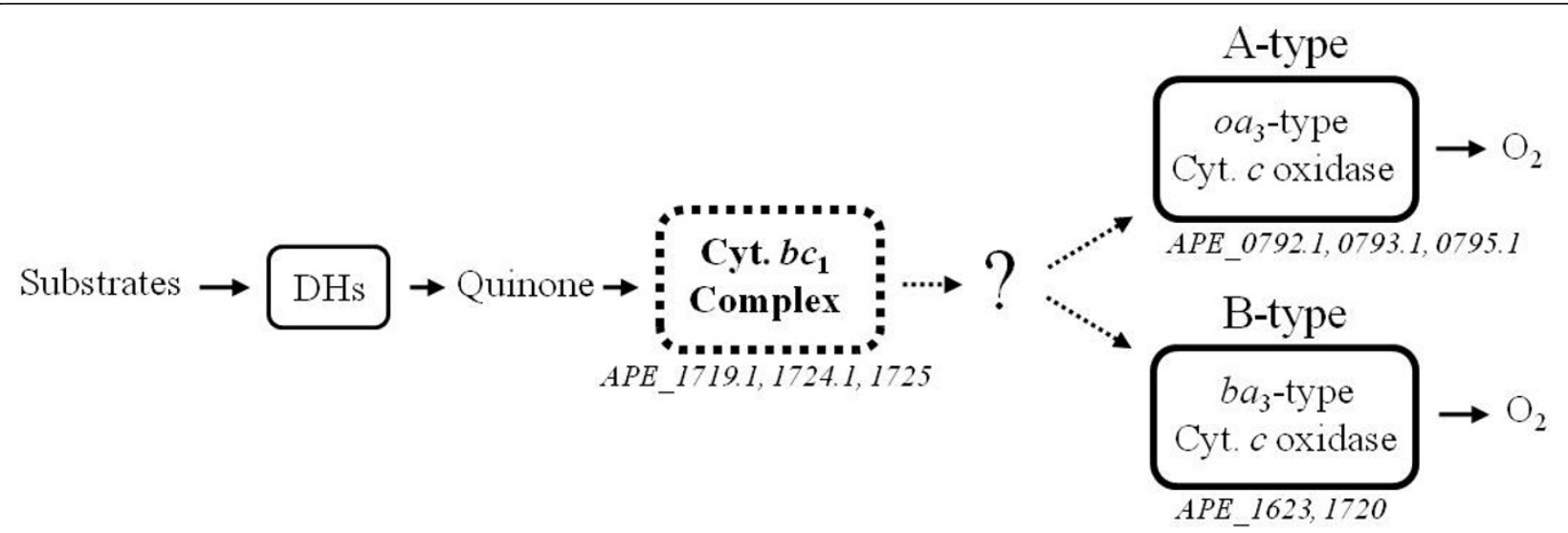

Figure 1 Schematic representation of the respiratory chain of Aeropyrum pernix K1. Genes encoding cytochrome $c$ oxidase and other respiratory components in the bacterium are indicated. ORFS APE_1719.1, APE_1724.1 and APE_1725 encode the cytochrome $c_{553}$ complex which was isolated in this study. ORFs APE_0792.1, APE_0793.1 and APE_0795.1, annotated as aoxABC genes, encode an A-type cytochrome $c$ oxidase, and ORFs APE_1623 and APE_1720 encode a B-type cytochrome $c$ oxidase. In the previous study of Ishikawa et al. (2002), these 2 terminal oxidases were designated as cytochrome $a a_{3}-$ and $b a_{3}$-type cytochrome $c$ oxidase, respectively.

binding motif, but its substrates have not been identified in the genome sequence.

An extremely haloalkaliphilic archaeon, Natronomonas pharaonis, uses a blue copper protein named halocyanin as a substrate for the terminal oxidase instead of cytochrome $c$ [11]. In S. acidocaldarius, a blue copper protein named sulfocyanin, which is a part of the SoxM supercomplex, is an intermediate in the electron transfer from the $b c_{1}$-analogous complex to the terminal oxidase [12]. However, no genes for blue copper proteins homologous to halocyanin or sulfocyanin have been found in the genome of $A$. pernix. Therefore, although these oxidases can use $N, N, N^{\prime}, N^{\prime}$-tetramethyl-p-phenylenediamine (TMPD) and/or bovine cytochrome $c$ as substrates in vitro, the authentic substrate of the two terminal oxidases is not known.

In contrast to terminal oxidases, complex III of archaea is not well-known and a canonical $b c_{1}$ complex has not been identified in any archaeal genome [13]. Among the subunit components of the $b c$ complex, both cytochrome $b$ and Rieske Fe/S protein are widely conserved, while the $c$-type cytochrome subunit has diverged into several classes, some of which show no sequence similarity to the class of cytochrome $c_{1}$ subunits [14]. This is compatible with the view that the functional and evolutionary core of the $b c$ complex includes cytochrome $b$ and the peripheral domain of the Rieske $\mathrm{Fe} / \mathrm{S}$ protein and that different $c$-type cytochromes have been recruited independently several times during molecular evolution. Generally, a $c$-type cytochrome has been reported only for a limited number of archaeal species, such as halophiles and thermoacidophiles, in contrast to $a / o$-type and $b$-type cytochromes, which seem ubiquitous in the respiratory chains of archaeal species.
Focusing on homologues of the cytochrome $b c$ components, cytochrome $b$ and Rieske Fe/S proteins are present in some archaeal species, such as Sulfolobus, and constitute supercomplexes with oxidase subunits [15], whereas cytochrome $c$ components are missing even in those organisms. Several $b c_{1}$-analogous complexes have been identified thus far in archaea such as Halobacterium salinarum [16] and Acidianus ambivalens [17].

In this study, we isolated $c$-type cytochromes from the membranes of $A$. pernix $\mathrm{K} 1$ cells and characterized the spectroscopic and enzymatic properties of the cytochromes. Our data indicate that the isolated $c$-type cytochrome is equivalent to the cytochrome $c$ subunit of the $b c$ complex and forms a supercomplex with cytochrome $c$ oxidase.

\section{Results}

Isolation of a membrane bound c-type cytochrome from A. pernix

We isolated a membrane bound $c$-type cytochrome from the membranes and designated it cytochrome $c_{553}$. A cytochrome oxidase was also isolated and designated cytochrome $o a_{3}$ oxidase, as shown later. A. pernix K1 cells were harvested in the early stationary phase, and membranes were prepared. The membrane proteins were solubilized with DDM and fractionated using 3step chromatography. In the first DEAE-Toyopearl column chromatography, the cytochrome $c_{553}$ and cytochrome $o a_{3}$ oxidase were mainly eluted with $100 \mathrm{mM}$ $\mathrm{NaCl}$ (data not shown). Also in the second Q-Sepharose column chromatography, the cytohrome $c_{553}$ eluted together with the cytochrome $o a_{3}$ oxidase at $\sim 200 \mathrm{mM}$ $\mathrm{NaCl}$ (Additional file 1). Interestingly, the peak fractions from Q-Sepharose, including cytochrome $c_{553}$ and $o a_{3}$ 
oxidase, showed not only TMPD oxidation activity (4.1 $\mu \mathrm{mol} \mathrm{min}^{-1} \mathrm{mg}^{-1}$ ) but also menaquinol oxidation activity $\left(1.0 \mu \mathrm{mol} \mathrm{min} \mathrm{mg}^{-1}\right)$. This suggested that cytochrome c553 and cytochrome $c$ oxidase interact. Subsequent chromatography on a hydroxyapatite column separated the cytochrome $c_{553}$ and cytochrome $o a_{3}$ oxidase into 2 peaks (Additional file 2). Table 1 shows a summary of the purification of cytochrome $c_{553}$. The $c$-type cytochrome content was enriched approximately 9.6-fold during the purification.

\section{Spectroscopic properties of cytochromes in A. pernix}

The redox difference spectrum of membranes showed $\alpha$-band peaks with maxima at 554 and $610 \mathrm{~nm}$ (Figure $2 \mathrm{a})$, derived from $c$ - and $a$-type cytochromes, respectively. The isolated cytochrome $c_{553}$ in the reduced state showed an absorption peak at $553 \mathrm{~nm}$ (Figure 2b, dotted line). The pyridine ferro-hemochrome spectrum showed $2 \alpha$-band peaks with maxima at 551 and $557 \mathrm{~nm}$, indicating the presence of heme $\mathrm{C}$ and heme $\mathrm{B}$ (Figure $2 \mathrm{~b}$, solid line) [18]. The redox spectrum of the cytochrome $o a_{3}$ oxidase showed $\alpha$-band peaks with maxima at 555 and $610 \mathrm{~nm}$ (Figure 2c, dotted line) and the pyridine ferro-hemochrome spectrum did $\alpha$-band peaks with maxima at 553 and $588 \mathrm{~nm}$ (Figure 2c, solid line), indicating the presence of heme $\mathrm{O}$ and heme $\mathrm{A}[18,19]$. To determine the heme species of the oxidase in more detail, total heme was extracted from the partially purified oxidase preparation and analyzed by mass spectrometry. We observed 3 peaks at molecular masses of 630.44, 888.94, and 920.98 (Figure 3). The molecular mass of 888.94 matches that of heme $\mathrm{O}_{\mathrm{p} 1}$, which was identified in Sulfolobus and other species [20], while the molecular mass of 920.98 matches that of heme $A_{s}$. The molecular mass of 630.44 matches that of heme $B$, which is probably contamination from other cytochromes, because the peak height is lower than those of hemes $\mathrm{O}_{\mathrm{p} 1}$ and $\mathrm{A}_{\mathrm{s}}$, and this oxidase does not contain $b$ type heme (Figure 2c). The difference spectrum of the CO-bound, reduced form minus the reduced form showed a peak and a trough at $595 \mathrm{~nm}$ and $611 \mathrm{~nm}$, respectively, in the $\alpha$ region (Figure $2 \mathrm{~d}$ ) and those at $432 \mathrm{~nm}$ and $444 \mathrm{~nm}$ in the $\gamma$ region (data not shown),

Table 1 Purification of $A$. pernix cytochrome $c_{553}$

\begin{tabular}{lccc}
\hline \multicolumn{1}{c}{ Steps } & $\begin{array}{c}\text { Total Protein } \\
(\mathbf{m g})\end{array}$ & \multicolumn{2}{c}{$\boldsymbol{c}$-type cytochrome } \\
\cline { 3 - 4 } & & Total $(\mathbf{n m o l})$ & Specific $\left(\mathbf{n m o l ~ \mathbf { ~ m } ^ { - 1 } )}\right.$ \\
\hline Membranes & 589 & 463 & 0.787 \\
DDM extract & 494 & 344 & 0.697 \\
DEAE-Toyopearl & 27.1 & 105 & 3.88 \\
Q-Sepharose & 21.1 & 30.8 & 1.46 \\
Hydroxyapatite & 2.00 & 15.1 & 7.55 \\
\hline
\end{tabular}

indicating that $\mathrm{CO}$ was bound to an $a$-type heme (Figure $2 \mathrm{~d}$ ), and thus the oxidase was designated a cytochrome $o a_{3}$-type.

\section{Polypeptide composition and enzyme activities}

SDS-PAGE showed mainly 3 polypeptide bands for cytochrome $c_{553}$ with apparent molecular masses of 40, 30, and $25 \mathrm{kDa}$ (Figure 4a, panel 1). The 25-kDa band was visualized with heme staining (Figure 4a, panel 2). We performed mass analysis for the 3 bands at 40, 30, and $25 \mathrm{kDa}$ using a MALDI-TOF/MS spectrometer. The 40and $30-\mathrm{kDa}$ polypeptides could not be identified. The $25-\mathrm{kDa}$ polypeptide, which was positive for heme staining, had a molecular mass of 21,344 (Figure 5). The theoretical mass of the $A P E_{-} 1719.1$ gene, which encodes the hypothetical cytochrome $c$ subunit of the $b c$ complex, was 20,813. The calculated mass of the $A P E_{-} 1719.1$ gene product, which is the hypothetical cytochrome $c$ polypeptide of the $b c$ complex, is 21,429. On a BN-PAGE gel, cytochrome $c_{553}$ migrated at 80 $\mathrm{kDa}$ as a single band (Figure $4 \mathrm{a}$, panel 3 ). The entire panel was excised and processed by two-dimensional SDS-PAGE. The $80-\mathrm{kDa}$ band consisted of 3 main polypeptides as shown by SDS-PAGE (Figure 4a, panel 1 and panel 3) indicating that these 3 polypeptides form a complex. For partially purified cytochrome $o a_{3}$ oxidase, SDS-PAGE showed 3 polypeptide bands with apparent molecular masses of 74, 40, and $25 \mathrm{kDa}$ (Figure $4 \mathrm{~b}$, panel 1). The 25-kDa band was visualized by heme staining, suggesting this band was derived from cytochrome $c_{553}$ (Figure $4 \mathrm{~b}$, panel 2). BN-PAGE showed a band at $140 \mathrm{kDa}$, which had TMPD oxidase activity, suggesting that the band contain a cytochrome $c$ oxidase (Figure 4b, panel 3). The $140-\mathrm{kDa}$ band was separated by SDS-PAGE and found to consist of 3 main polypeptides as shown by SDS-PAGE (Figure 4b, panel 1 and panel 3).

The isolated cytochrome $o a_{3}$ oxidase had TMPD and yeast cytochrome $c$ oxidation activity, with values of 132 and $0.68 \mu \mathrm{mol} \mathrm{min} \mathrm{mg}^{-1}$, respectively, while the cytochrome $c_{553}$ complex did not show any oxidase activity. On the other hand, cytochrome $c_{553}$ oxidized menaquinol and reduced yeast cytochrome $c\left(3.7 \mu \mathrm{mol} \mathrm{min}^{-1}\right.$ $\mathrm{mg}^{-1}$ ), i.e. showed activity similar to that of quinone: cytochrome $c$ oxidoreductase, while isolated cytochrome $o a_{3}$ did not oxidize menaquinol. Interestingly, after adding the fractions containing cytochrome $c_{553}$ to cytochrome $o a_{3}$ oxidase, TMPD oxidase activity increased 5.0-fold (132 $\mu \mathrm{mol} \mathrm{min} \mathrm{mg}^{-1}$ vs $664 \mu \mathrm{mol} \mathrm{min}{ }^{-1} \mathrm{mg}^{-1}$ ).

\section{Discussion}

In this study, we isolated a membrane bound cytochrome $c_{553}$ from the strictly aerobic hyperthermophilic archaeon, A. pernix. SDS-PAGE analysis showed 3 


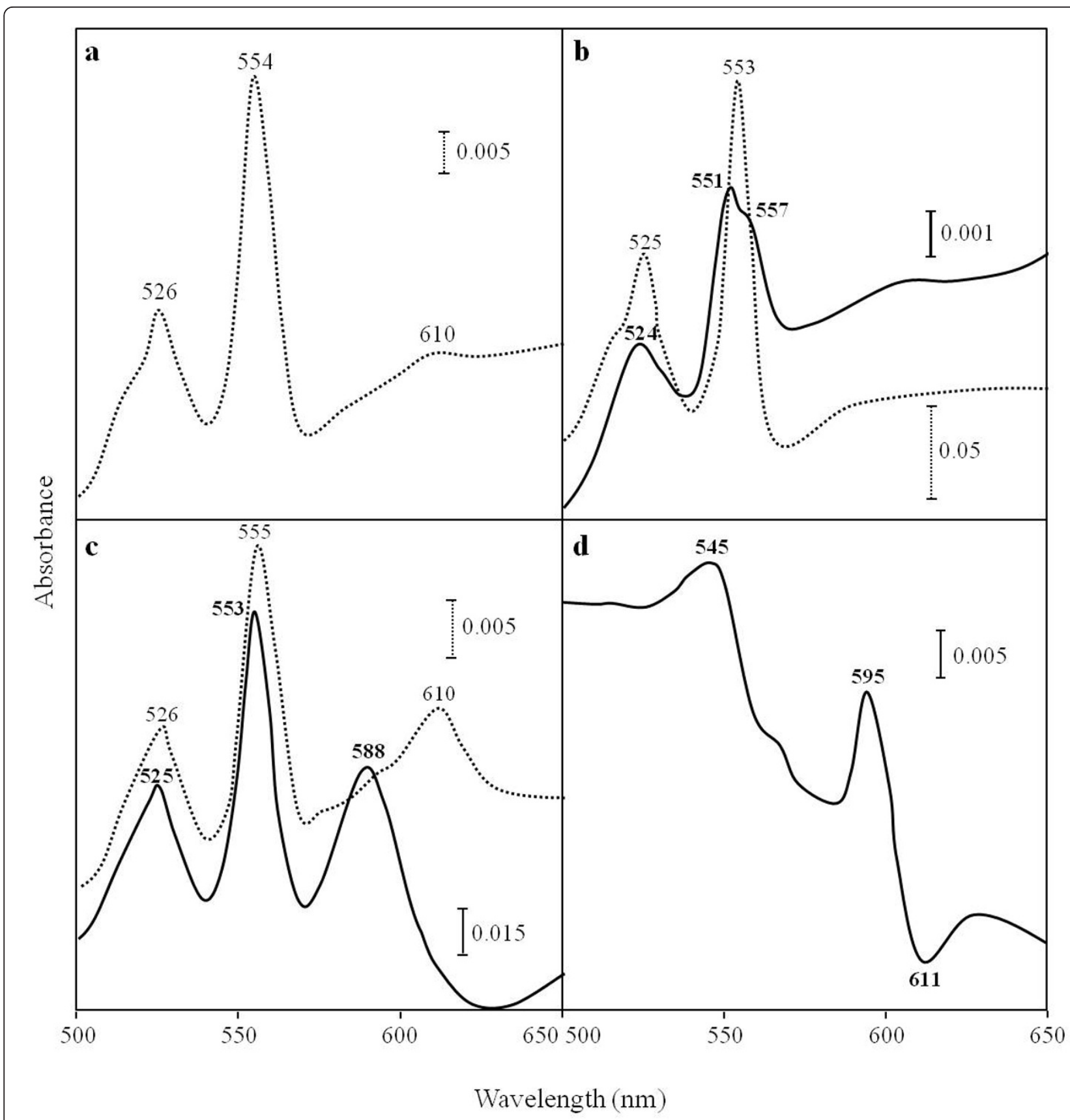

Figure 2 Spectra of cytochromes in A. pernix. Difference spectrum in the sodium dithionite-reduced form minus the air-oxidized form (dotted line) and pyridine ferro-hemochromes (solid line) of membranes (a), cytochrome $c_{553}$ (b), and cytochrome $0_{3}$ oxidase (c). To measure a spectrum of membranes, they were solubilized with 5\% (w/v) Triton X-100, as described in Materials and Methods. Difference spectrum of the CO-reduced minus the reduced forms of cytochrome $0 a_{3}$ oxidase $(\mathbf{d})$. The partially purified oxidase was reduced with sodium dithionite (baseline) and then bubbled with CO gas for 1 min.

bands at apparent molecular masses of 40, 30, and 25 $\mathrm{kDa}$ (Figure 4a, panel 1). The measured molecular mass of the $25-\mathrm{kDa}$ band, which was positive for heme staining, was close to the calculated molecular mass for the hypothetical cytochrome $c$ subunit encoded by ORF $A P E_{-} 1719.1$ (Figure 5). Cytochrome $c_{553}$ preparations contained heme $\mathrm{B}$ and heme $\mathrm{C}$ (Figure $2 \mathrm{~b}$, solid line) and catalyzed electron transfer from menaquinone to yeast cytochrome $c$. On the basis of these results, we concluded that cytochrome $c_{553}$ was part of the cytochrome $b c$ complex and that the 3 bands identified by SDS-PAGE analysis corresponded to cytochrome $b$, 


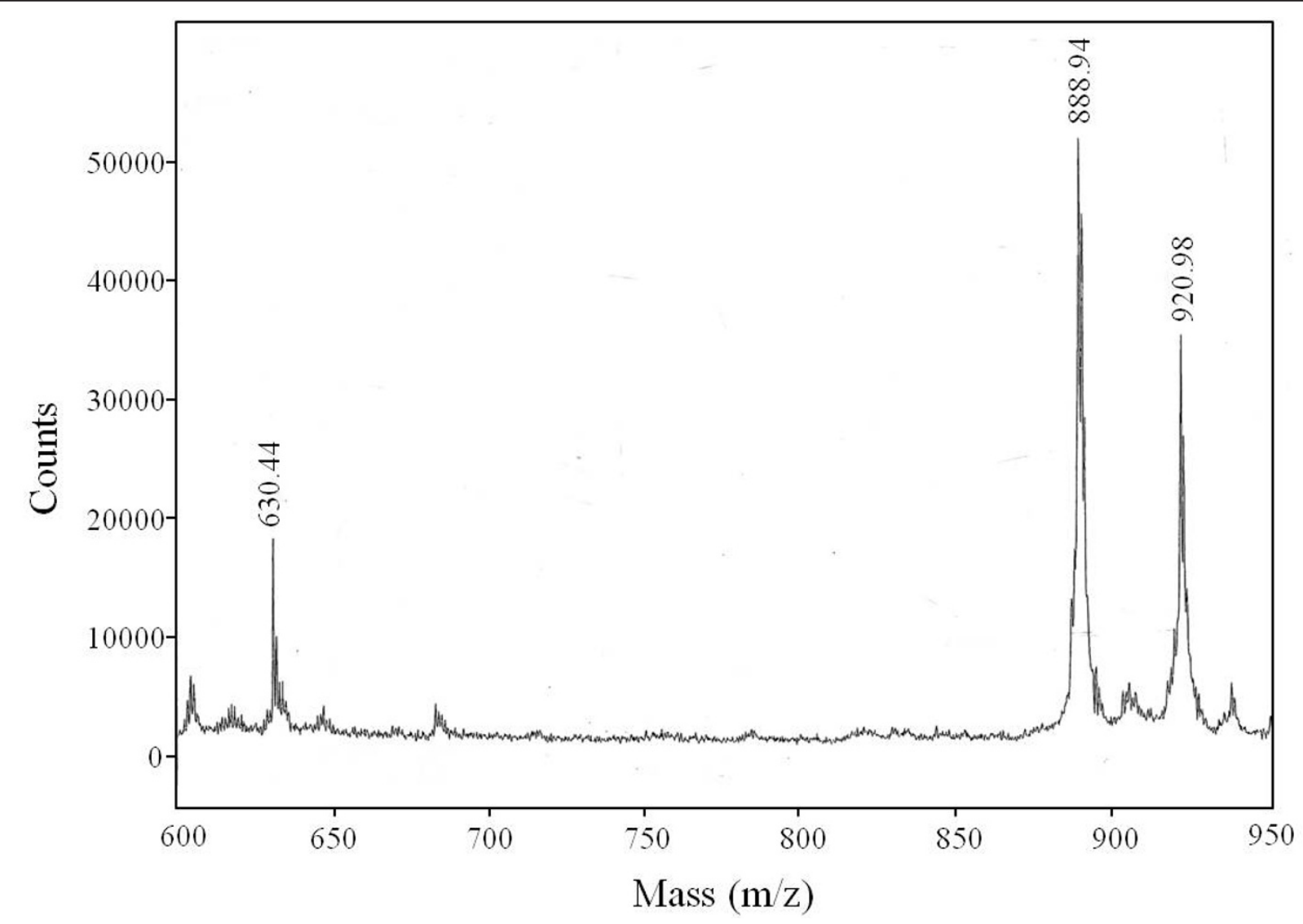

Figure 3 Heme analysis by MALDI-TOF mass spectrometry of partially purified cytochrome o $a_{3}$ oxidase from A. pernix. Heme was extracted from the oxidase preparation by shaking vigorously with acetone- $\mathrm{HCl}$, followed by extraction with ethyl acetate. The extracted heme was analyzed by MALDI-TOF mass spectrometry as detailed in the "Materials and Methods".

Rieske/FeS, and cytochrome $c$ subunits. Data from BNPAGE analysis supported the idea that these 3 bands are part of the $b c$ complex (Figure $4 a$, panel 3 ). The gene for the cytochrome $c$ polypetide, $A P E_{-} 1719.1$ contains a $\mathrm{CXXCHX}_{\mathrm{n}} \mathrm{M}$ motif but does not show high sequence similarity to cytochrome $c_{1}$ or the other classes of bacterial or eukaryotic $c$-type components. It is generally difficult to isolate $b c$ complexes from membranes because of their general instability, but the heat stability of this enzyme probably permitted its isolation in this study.

We also isolated a cytochrome $o a_{3}$-type cytochrome $c$ oxidase from $A$. pernix membranes. Based on polypeptide sizes, the upper 2 bands identified by SDS-PAGE (Figure 4b, panel 1) probably corresponded to AoxA (subunit I + III) and AoxB (subunit II). Thus, the partially purified cytochrome $o a_{3}$ oxidase here is likely the A-type oxidase identified by Ishikawa et al. previously [10]. Interestingly, cytochrome $o a_{3}$ oxidase comigrated with the $b c$ complex through the DEAE-Toyopearl and Q-Sepharose chromatographies, but the enzymes were separated during the subsequent hydroxyapatite chromatography (Figs. S1 and S2). Furthermore, peak fractions from the Q-Sepharose column, which included the $b c$ complex and cytochrome $o a_{3}$ oxidase, had menaquinol oxidase activity. These findings suggest that cytochrome $0 a_{3}$ oxidase forms a supercomplex with the $b c$ complex as observed in some species, such as thermophilic Bacillus PS3 [21], Corynebacterium glutamicum [22], and S. acidocaldarius [15,23].

\section{Conclusions}

Here, we showed that $A$. pernix has a $b c$ complex which includes a $c$-type cytochrome, and that the $b c$ complex forms supercomplex with the cytochrome $o a_{3}$ oxidase. An electron donor candidate for cytochrome $c$ oxidase, such as a blue copper protein, has not yet been identified in the whole genome data of this archaeon. Taken together, it might be suggested that the cytochrome $c_{553}$ is the direct electron donor for the oxidase, which would explain the apparent lack of a donor such as a copper protein. We are currently trying to identify an authentic substrate between a $b c$ complex and terminal oxidase. 
$\mathbf{a}$

(kDa)

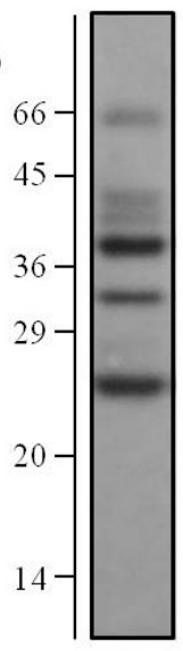

1

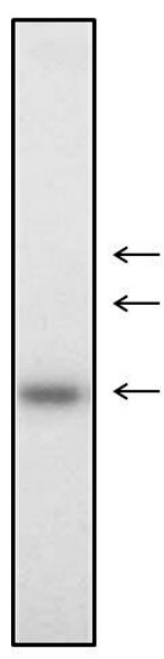

2

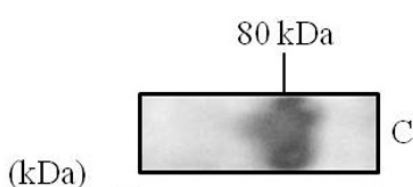

$\mathrm{CBB}$

$\mathrm{kDa})$

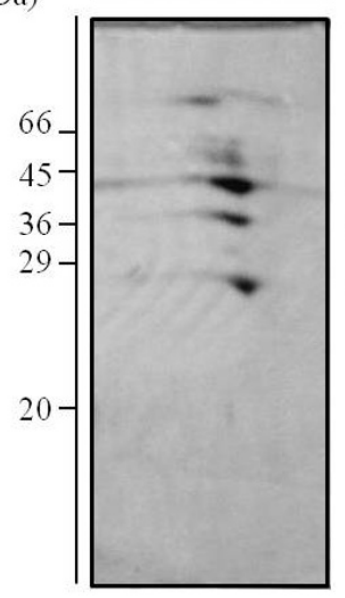

3
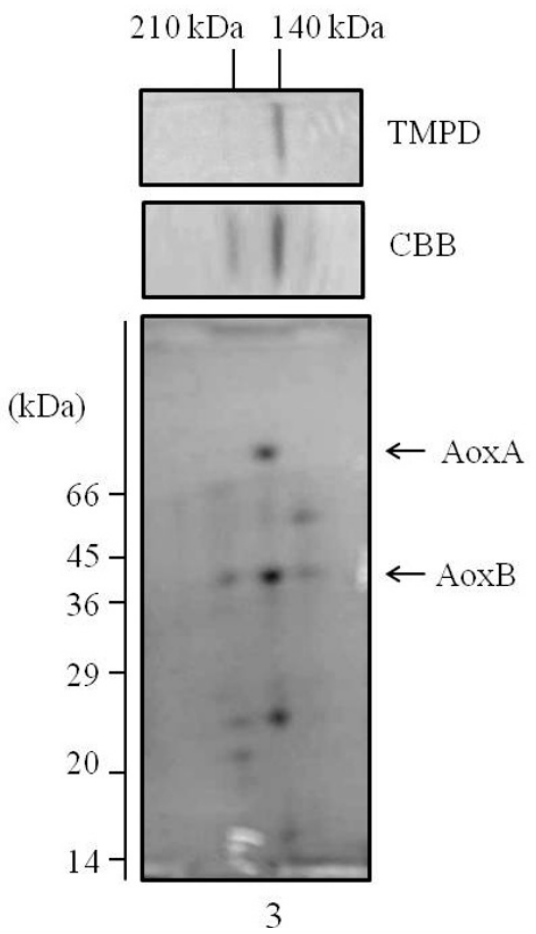

TMPD

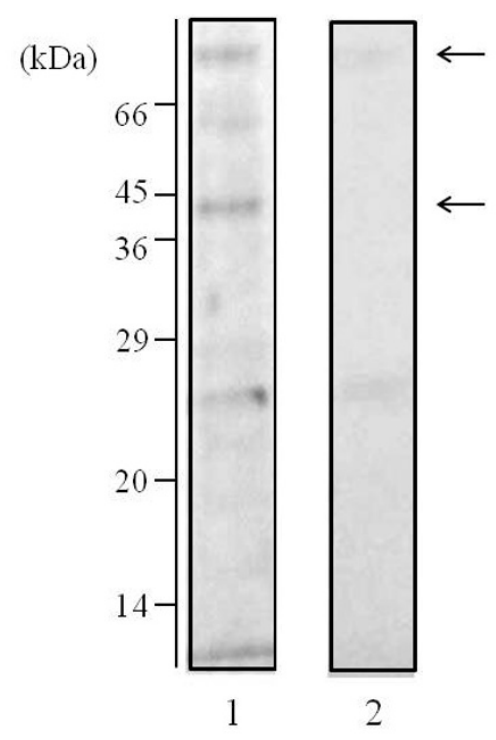

Figure 4 SDS-PAGE (panel 1 and 2) and Two-dimensional electrophoresis analysis (panel 3) of the cytochrome $c_{553}$ (a) and cyothcrome $\mathrm{oa}_{3}$ oxidase (b) from A. pernix. The acrylamide concentration of the SDS-PAGE gel was $13.5 \%$. The gel was stained for protein with CBB (panel 1) and for heme with o-toluidine in the presence of $\mathrm{H}_{2} \mathrm{O}_{2}$ (panel 2). The samples were analyzed by BN-PAGE (horizontal) and then SDS-PAGE (vertical, panel 3). A 5-18\% acrylamide gradient gel was used for native PAGE, and the gels were stained with CBB. The cytochrome o $a_{3}$ oxidase was revealed by its TMPD oxidation activity (b panel 3). The acrylamide concentration of the second dimension SDS-PAGE gel was 15\%, and the gels were stained with CBB. Side bars indicate the molecular mass standards. The arrows indicate the corresponding subunits of the cytochrome $C_{553}$ and cytochrome $o a_{3}$ oxidase. 


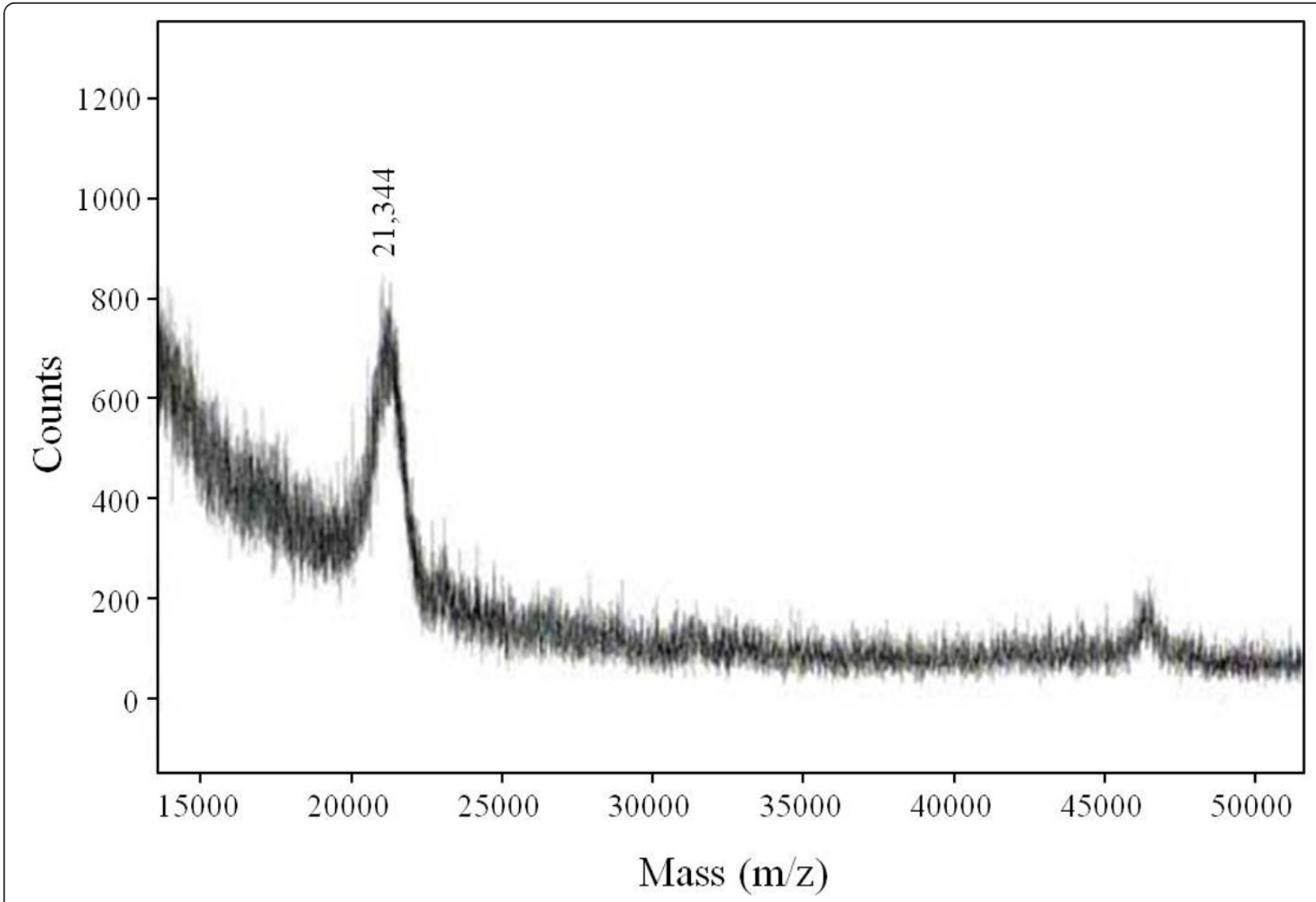

Figure 5 MALDI-TOF mass spectrum of cytochrome $c_{553}$ from $\boldsymbol{A}$. pernix. Partially purified cytochrome $c_{553}$ was separated by SDS-PAGE (Figure 4a, panel 1), and the 25-kDa band was extracted from the acrylamide gel. Mass spectrum analysis was performed as detailed in the Materials and Methods.

\section{Methods}

\section{Bacterial strain and growth conditions}

A. pernix $\mathrm{K} 1$ cells were kindly provided by Dr. Yosuke Koga, University of Occupational and Environmental Health, Japan. A pernix was aerobically grown in $5 \times \mathrm{T}$ medium [2.8\% (w/v) NaCl, $0.067 \%(\mathrm{w} / \mathrm{v}) \mathrm{KCl}, 0.55 \%(\mathrm{w} /$ v) $\mathrm{MgCl}_{2} \cdot 6 \mathrm{H}_{2} \mathrm{O}, 0.69 \%(\mathrm{w} / \mathrm{v}) \mathrm{MgSO}_{4} \cdot 7 \mathrm{H}_{2} \mathrm{O}, 0.15 \%(\mathrm{w} / \mathrm{v})$ $\mathrm{CaCl}_{2}, 0.1 \%(\mathrm{w} / \mathrm{v}) \mathrm{Na}_{2} \mathrm{O}_{3} \mathrm{~S} \cdot 5 \mathrm{H}_{2} \mathrm{O}, 0.5 \%$ (w/v) Trypticase Peptone, $0.1 \%(\mathrm{w} / \mathrm{v})$ Yeast Extract, $\mathrm{pH} 7.0]$ at $90^{\circ} \mathrm{C}$. The preculture was carried out for $48 \mathrm{~h}$ in a Sakaguchi-flask containing $50-\mathrm{ml}$ of medium, and a $50-\mathrm{ml}$ aliquot was inoculated into a 1-L culture in a 3-L baffled flask. Cultures were incubated for about $48 \mathrm{~h}$ with vigorous shaking $(150 \mathrm{rpm})$ until they attained the early stationary phase of growth. The cells were collected by centrifugation at $5,000 \times \mathrm{g}$ for $20 \mathrm{~min}$.

\section{Membrane preparation}

The cells were washed twice with $20 \mathrm{mM} \mathrm{NaP}_{\mathrm{i}}$ buffer at pH 7.0 and re-suspended in the same buffer. The cells were disrupted by sonication with an Ultrasonic Disrupter UD-201 (TOMY, Tokyo) using a 50\% duty cycle at output 3 for 20 sec 3 times. The broken cells were precipitated by centrifugation at $16,000 \times \mathrm{g}$ for $20 \mathrm{~min}$ at $4^{\circ} \mathrm{C}$. The precipitate was resuspended in $10 \mathrm{mM}$ Tris$\mathrm{HCl}$ buffer at $\mathrm{pH}$ 8.0, which contained a final concentration of $10 \mathrm{mM} \mathrm{MgCl}_{2}$ and $10 \mu \mathrm{g} \mathrm{ml}^{-1}$ DNase, and incubated at $37^{\circ} \mathrm{C}$ for $30 \mathrm{~min}$. To remove unbroken cells, the suspension was centrifuged at $1,000 \times \mathrm{g}$ for $5 \mathrm{~min}$ at $4^{\circ} \mathrm{C}$. The supernatant was then centrifuged at $100,000 \times$ $\mathrm{g}$ for $20 \mathrm{~min}$ at $4^{\circ} \mathrm{C}$. The precipitate was resuspended in $20 \mathrm{mM} \mathrm{NaP}_{\mathrm{i}}$ at $\mathrm{pH}$ 7.0; this suspension was designated as the membrane fraction.

\section{Solubilization and separation of cytochromes}

The membranes were suspended in buffer containing 1 $\mathrm{M} \mathrm{LiCl}$ and $20 \mathrm{mM} \mathrm{NaP}_{\mathrm{i}}$ at $\mathrm{pH} 7.0$, and then collected by centrifugation. The membrane proteins were solubilized at $10 \mathrm{mg}$ protein $\mathrm{ml}^{-1}$ in $1 \%(\mathrm{w} / \mathrm{v}) n$-dodecyl- $\beta$-Dmaltoside (DDM) in the presence of $0.3 \mathrm{M} \mathrm{NaCl}, 20$ $\mathrm{mM} \mathrm{NaP}$ at $\mathrm{pH}$ 7.0, and several protease inhibitors [1 $\mathrm{mM}$ ethylenediamine- $N, N, N^{\prime}, N^{\prime}$-tetraacetic acid (EDTA), $0.1 \mathrm{mM}$ phenylmethylsulfonyl fluoride (PMSF), and 0.5 $\mathrm{mM}$ benzamidine at final concentrations]. The mixture 
was centrifuged at $100,000 \times \mathrm{g}$ for $30 \mathrm{~min}$, and the supernatant was dialyzed against $10 \mathrm{mM}$ Tris- $\mathrm{HCl}$ at $\mathrm{pH}$ 7.0.

Cytochromes were separated into 2 components using 3 consecutive chromatography columns: DEAE-Toyopearl, Q-Sepharose, and hydroxyapatite. In brief, the solubilized protein was applied to a DEAE-Toyopearl column after dialysis. The adsorbed proteins were eluted with 3 column volumes of buffer containing 0.1\% DDM, $10 \mathrm{mM}$ Tris- $\mathrm{HCl}$ at $\mathrm{pH} 7.0$, and an increasing concentration of $\mathrm{NaCl}$ (stepwise gradient of 20,50,100, 200, 300 , and $500 \mathrm{mM}$ ). The peak fractions were dialyzed against $10 \mathrm{mM}$ Tris- $\mathrm{HCl}$ at $\mathrm{pH} 7.0$ and were applied to a Q-Sepharose column. The proteins were eluted with 15 column volumes of buffer containing $0.1 \%$ DDM, 10 $\mathrm{mM}$ Tris- $\mathrm{HCl}$ at $\mathrm{pH} 7.0$, and an increasing concentration of $\mathrm{NaCl}$ (linear gradient of 0-300 mM; Additional file 1). The peak fractions were applied to a hydroxyapatite column for separation. The proteins were eluted with 3 column volumes of buffer containing 0.1\% DDM and an increasing concentration of $\mathrm{NaP}_{\mathrm{i}}$ at $\mathrm{pH} 7.0$ (stepwise gradient of $20,50,100,150,200,300$, and 400 $\mathrm{mM}$; Additional file 2).

\section{Enzyme activities}

Cytochrome oxidase activity was assayed at $60^{\circ} \mathrm{C}$ by measuring oxidation of a yeast cytochrome $c$ (Sigma-Aldrich, St. Louis MO), which had been reduced with sodium dithionite, in a final volume $800 \mu \mathrm{L}$ containing a suitable amount of enzyme, $20 \mathrm{mM} \mathrm{NaP}$ at $\mathrm{pH} 7.0$, and $10 \mu \mathrm{M}$ yeast cytochrome $c$. The oxidation of reduced cytochrome $c$ was followed by measuring the decrease in absorbance at $549 \mathrm{~nm}$, and activity was calculated using a millimolar absorption coefficient of $21.2 \mathrm{mM}^{-1} \mathrm{~cm}^{-1}$ [24].

$N, N, N^{\gamma}, N^{3}$-Tetramethyl- $p$-phenylenediamine (TMPD) oxidase activity was assayed by measuring the increase in absorbance at $562 \mathrm{~nm}$ using a mixture of $25 \mathrm{mM}$ TMPD, $0.1 \mathrm{M} \mathrm{NaCl}$, and $50 \mathrm{mM} \mathrm{NaP}$ at $\mathrm{pH} 6.5$, and calculated using a millimolar absorption coefficient of $10.5 \mathrm{mM}^{-1} \mathrm{~cm}^{-1}$. To avoid the auto-oxidation of TMPD, the assay was performed at $40^{\circ} \mathrm{C}$.

Menaquinol oxidase activity was assayed at $40^{\circ} \mathrm{C}$ by measuring the oxidation rate of menaquinol-1, which had been reduced with sodium dithionite, in a final volume of $700 \mu \mathrm{L}$ containing a suitable amount of enzyme, $20 \mathrm{mM}$ $\mathrm{NaP}_{\mathrm{i}}$ at $\mathrm{pH} 7.0,0.1 \%(\mathrm{w} / \mathrm{v}) \mathrm{DDM}, 1 \mathrm{mM}$ EDTA, and 0.2 $\mathrm{mM}$ menaquinol-1. The oxidation of reduced menaquinone was followed by measuring the increase in absorbance at $270.7 \mathrm{~nm}$, and the activity was calculated using a millimolar absorption coefficient of $8.13 \mathrm{mM}^{-1} \mathrm{~cm}^{-1}$.

\section{Electrophoretic analyses}

Blue-native polyacrylamide gel electrophoresis (BNPAGE) was performed according to the method of
Schägger et al. [25]. Nondenaturating electrophoresis was started at $100 \mathrm{~V}$ until the sample was within the stacking gel and continued with the voltage and current limited to $350 \mathrm{~V}$ and $15 \mathrm{~mA}$, respectively. For twodimensional analysis, a slice of the BN-PAGE gel was excised and soaked in $1 \%$ sodium dodecyl sulfate (SDS) and $1 \%$ mercaptoethanol buffer for $1 \mathrm{~h}$ and then embedded in a separating gel containing 15\% acrylamide. Two-dimensional analysis was performed at room temperature with the current limited to $20 \mathrm{~mA}$. SDSPAGE was performed according to the method of Laemmli [26]. The gel was stained for protein with $\mathrm{CBB}$ and for heme with $o$-toluidine in the presence of $\mathrm{H}_{2} \mathrm{O}_{2}$. Gels were immersed in a solution containing $1 \%(\mathrm{w} / \mathrm{v})$ o-tolidine, $80 \%(\mathrm{v} / \mathrm{v}) \mathrm{CH}_{3} \mathrm{OH}$ and $10 \%(\mathrm{v} / \mathrm{v}) \mathrm{CH}_{3} \mathrm{COOH}$ for $10 \mathrm{~min}$, and then $\mathrm{H}_{2} \mathrm{O}_{2}$ was added at final concentration of $1 \%(\mathrm{v} / \mathrm{v})$.

\section{Mass analysis}

Matrix-assisted laser desorption ionization, time-of-flight (MALDI-TOF) mass spectrometry of proteins was performed using 2- (4-hydroxyphenylazo) benzoic acid (HABA) as the matrix as described by Ghaim et al. [27]. The cytochromes extracted from the SDS-PAGE gel were precipitated with trichloroacetic acid (TCA) and were dissolved in 99\% formic acid before mixing at a 1:5 ratio with a $50 \%$ acetonitrile solution containing $1.3 \mathrm{mg}$ HABA ml ${ }^{-1}$ and $0.1 \%$ trifluoroacetic acid. The mixture was spotted onto a sample plate and analyzed using a MALDI-TOF mass spectrometer.

For heme analysis, heme was extracted from partially purified cytochrome $o a_{3}$ oxidase with acetone containing $10 \%$ concentrated $\mathrm{HCl}$ as described previously [28]. After centrifugation, the heme in the supernatant was extracted with ethyl acetate. The heme-containing upper phase was removed, and the ethyl acetate was evaporated under a stream of nitrogen. Heme was dissolved in $30 \%$ acetonitrile and then mixed at a 1:1 ratio with a $50 \%$ acetonitrile solution containing $10 \mathrm{mg} \alpha$-cyano-4hydroxy cinnamic acid $\mathrm{ml}^{-1}$ and $0.1 \%$ trifluoroacetic acid. The mixture was spotted onto a sample plate and analyzed using a MALDI-TOF mass spectrometer.

\section{Additional analyses}

Absorption spectra were measured with a recording spectrophotometer (Beckman DU70) at room temperature. Spectra of pyridine ferro-hemochromes were measured in the presence of $10 \%(\mathrm{v} / \mathrm{v})$ pyridine, $0.05 \mathrm{~N}$ $\mathrm{NaOH}$, and $1 \%(\mathrm{w} / \mathrm{v})$ SDS. For membrane preparations, samples were mixed with $5 \%(\mathrm{w} / \mathrm{v})$ Triton X-100 and centrifuged at $100,000 \times \mathrm{g}$ for $20 \mathrm{~min}$ at $4^{\circ} \mathrm{C}$, as a common procedure to minimize turbidity. Protein concentration was determined using a modified Lowry method [29]. 


\section{Additional material}

Additional file 1: Supplemental Figure S1- Partial purification of cytochrome $b c-\mathrm{oa}_{3}$ supercomplex with Q-Sepharose. DEAE-Toyopearl chromatography fractions containing both cytochrome $c_{553}$ and cytochrome $\mathrm{Oa}_{3}$ oxidases were applied to a Q-Sepharose column for further purification. The cytochrome $c_{553}$ eluted together with the cytochrome $\mathrm{Oa}_{3}$ oxidase at $\sim 200 \mathrm{mM} \mathrm{NaCl}$. The peak fraction catalyzed both TMPD oxidation and menaquinol oxidation

Additional file 2: Supplemental Figure S2- Separation of the cytochrome $b c$ complex from cytochrome $b c-o a_{3}$ supercomplex with hydroxyapatite column chromatography. Q-Sepharose fractions containing both cytochrome $c_{553}$ and cytochrome $o a_{3}$ oxidases were applied to a hydroxyapatite column for separation cytohcrome $c_{553}$ and cytochrome $o a_{3}$ oxidase. The cytochrome $c_{553}$ was mainly eluted with 50 $\mathrm{mM} \mathrm{NaP}$, and the TMPD oxidase activity was mainly eluted with $300 \mathrm{mM}$ $\mathrm{NaP}_{\mathrm{i}}$

\section{Abbreviations}

DDM: $n$-dodecyl- $\beta$-D-maltoside; DCIP: 2,6-dichloroindophenol; menadione, 2methyl-1,4-naphtoquinone; MALDI: matrix-assisted laser desorption ionization; TOF: time-of-flight; TMPD: $N, N, N^{\prime}, N^{\prime}$-tetramethyl-pphenylenediamine; BN: blue native; SDS: sodium dodecyl sulfate; PAGE: polyacrylamide gel electrophoresis.

\section{Acknowledgements}

The authors thank Prof. Yosuke Koga (University of Occupational and Environmental Health, Japan) for providing Aeropyrum pernix K1 cells.

\section{Author details}

'Department of Bioscience and Bioinformatics, Kyushu Institute of Technology, Kawazu 680-4, lizuka, Fukuoka-ken 820-8502, Japan ${ }^{2}$ Department of Chemistry, School of Medicine, Kyorin University, Mitaka, Tokyo 181-8611, Japan.

\section{Authors' contributions}

YK carried out the majority of the experimental work, analyzed the data and participated in drafting the manuscript. JS conceived the study, and participated in its design and coordination and helped to draft the manuscript. All authors read and approved the final manuscript.

Received: 3 December 2010 Accepted: 14 March 2011

Published: 14 March 2011

\section{References}

1. Sako Y, Nomura N, Uchida A, Ishida Y, Morii H, Koga Y, Hoakai T, Maruyama T: Aeropyrum pernix gen. nov., sp. nov., a novel aerobic hyperthermophilic archaeon growing at temperatures up to $100^{\circ} \mathrm{C}$. Int J Syst Bacteriol 1996, 46:1070-1077.

2. Kawarabayasi $Y$, Hino $Y$, Horikawa $H$, et al: Complete genome sequence of an aerobic hyper-thermophilic crenarchaeon, Aeropyrum pernix K1. DNA Res 1999, 6:83-101.

3. Sakamoto J, Sone N: Biochemical and Molecular Features of Terminal Oxidases. In Respiration in archaea and bacteria. Volume 1. Edited by: Zannoni D. The Netherlands: Kluwer Academic Publishers; 2004:87-113.

4. Castresana J, Saraste M: Evolution of energetic metabolism: the respiration-early hypothesis. Trends Biochem Sci 1995, 20:443-448.

5. Pereira MM, Santana M, Teixeira M: A novel scenario for the evolution of haem-copper oxygen reductases. Biochim Biophys Acta 2001, 1505:185-208.

6. Sakamoto J, Handa Y, Sone N: A novel cytochrome $b(o / a)_{3}$-type oxidase from Bacillus stearothermophilus catalyzes cytochrome $c-551$ oxidation. J Biochem 1997, 122:764-771.

7. Nikaido K, Noguchi S, Sakamoto J, Sone N: The $c b a A B$ genes for bo ${ }_{3}$-type cytochrome $c$ oxidase in Bacillus stearothermophilus. Biochim Biophys Acta 1998, 1397:262-267.

8. Zimmermann BH, Nitsche $\mathrm{Cl}$, Fee JA, Rusnak F, Münck E: Properties of a copper-containing cytochrome $b a_{3}$ : a second terminal oxidase from the extreme thermophile Thermus thermophilus. Proc Natl Acad Sci USA 1988, 85:5779-5783.

9. Lübben M, Amaud S, Castresana J, Warne A, Albracht SPJ, Saraste M: A second terminal oxidase in Sulfolobus acidocaldarius. Eur J Biochem 1994, 224:151-159

10. Ishikawa R, Ishido Y, Tachikawa A, Kawasaki H, Matsuzawa H, Wakagi T: Aeropyrum pernix K1, a strictly aerobic and hyperthermophilic archaeon, has two terminal oxidases, cytochrome $b a_{3}$ and cytochrome $a a_{3}$. Arch Microbiol 2002, 179:42-49.

11. Scharf B, Engelhard M: Halocyanin, an archaebacterial blue copper protein (type I) from Natronobacterium pharaonis. Biochemistry 1993, 32:12894-12900

12. Komorowski L, Schäfer G: Sulfocyanin and subunit II, two copper proteins with novel features, provide new insight into the archaeal SoxM oxidase supercomplex. FEBS Lett 2001, 487:351-355.

13. Schäfer G: Respiratory chains in Archaea: From Minimal Systems to Supercomplexes. In Respiration in archaea and bacteria. Volume 2. Edited by: Zannoni D. The Netherlands: Kluwer Academic Publishers; 2004:1-33.

14. Sone N, Hägerhäll C, Sakamoto J: Aerobic respiration in the Gram-Positive bacteria. In Respiration in archaea and bacteria. Volume 2. Edited by: Zannoni D. The Netherlands: Kluwer Academic Publishers; 2004:35-62.

15. Komorowski L, Verheyen W, Schäfer G: The archaeal respiratory supercomplex SoxM from S. acidocaldarius combines features of quinole- and cytochrome c-oxidases. Biol Chemistry 2002, 383:1791-1799.

16. Sreeramulu K, Schmidt CL, Schafer G, Anemuller S: Studies of the electron transport chain of the euryarchaeon Halobacterium salirum: indications for a type II NADH dehydrogenase and a complex III analog. J Bioenerg Biomembranes 1998, 30:443-453.

17. Bandeiras TM, Refojo PN, Todorovic S, Murgida DH, Hildebrandt P, Bauer $C$ Pereira MM, Kletzin A, Teixeira M: The cytochrome ba complex from the thermoacidophilic crenarchaeote Acidianus ambivalens is an analog of bc $c_{1}$ complexes. Biochim Biophys Acta 2009, 1787:37-45.

18. Berry EA, Trumpower BL: Simultaneous determination of hemes $a, b$, and c from pyridine hemochrome spectra. Anal Biochem 1987, 161:1-15.

19. Puustinen $A$, Wikström $M$ : The heme groups of cytochrome o from Escherichia coli. Proc Natl Acad Sci USA 1991, 88:6122-6126.

20. Lübben M, Morand K: Novel prenylated hemes as cofactors of cytochrome oxidases. Archaea have modified hemes A and O. J Biol Chem 1994, 269:21473-21479.

21. Sone N, Sekimachi M, Kutoh E: Identification and properties of a quinol oxidase super-complex composed of a $b c_{1}$ complex and cytochrome oxidase in the thermophilic bacterium PS3. J Biol Chem 1987, 262:15386-15391.

22. Niebisch A, Bott M: Purification of a cytochrome $b c-a a_{3}$ supercomplex with quinol oxidase activity from Corynebacterium glutamicum. Identification of a fourth subunity of cytochrome $a a_{3}$ oxidase and mutational analysis of diheme cytochrome $c_{1}$. J Biol Chem 2003, 278:4339-4346.

23. Lübben M, Warne A, Albracht SP, Saraste M: The purified SoxABCD quinol oxidase complex of Sulfolobus acidocaldarius contains a novel haem. Mol Microbiol 1994, 13:327-335.

24. Yonetani T, Ray GS: Studies on cytochrome $c$ peroxidase. I. Purification and some properties. J Biol Chem 1965, 240:4503-4508.

25. Schägger $\mathrm{H}$, Cramer WA, von Jagow G: Analysis of molecular masses and oligomeric states of protein complexes by blue native electrophoresis and isolation of membrane protein complexes by two-dimensional native electrophoresis. Anal Biochem 1994, 217:220-230.

26. Laemmli UK: Cleavage of structural proteins during the assembly of the head of bacteriophage T4. Nature 1970, 227:680-685.

27. Ghaim JB, Tsatsos PH, Katsonouri A, Mitchell DM, Salcedo-Hernandez R, Gennis RB: Matrix-assisted laser desorption ionization mass spectrometry of membrane proteins: demonstration of a simple method to determine subunit molecular weights of hydrophobic subunits. Biochim Biophys Acta 1997, 1330:113-120.

28. Sone N, Fujiwara Y: Effects of aeration during growth of Bacillus stearothermophilus on proton pumping activity and change of terminal oxidase. J Biochem 1991, 107:1016-1021.

29. Lowry OH, Rosebrough NJ, Farr AL, Randall RJ: Protein measurement with the Folin phenol reagent. J Biol Chem 1951, 193:265-275.

doi:10.1186/1471-2180-11-52

Cite this article as: Kabashima and Sakamoto: Purification and biochemical properties of a cytochrome $b c$ complex from the aerobic hyperthermophilic archaeon Aeropyrum pernix. BMC Microbiology 2011 11:52. 